\title{
Knowledge and Awareness about Colorectal Cancer and Its Screening Guidelines among Doctors in Al Ahsa, Eastern Province, Kingdom of Saudi Arabia
}

\author{
Bathula Surendra ${ }^{1}$, Muhammad Mujtaba Hashir ${ }^{1}$, Fahad Salman Al Harbi ${ }^{1}$, Mohammed Jassim Al Nuwaysir ${ }^{1}$, \\ Khalid Majed Al Khaldi ${ }^{1} \&$ Abdul Rahman Majid Al Qahtani ${ }^{1}$ \\ ${ }^{1}$ Department of Internal Medicine, College of Medicine, King Faisal University, Hofuf, Kingdom of Saudi Arabia \\ Correspondence: Muhammad Mujtaba Hashir, MCPS (Internal Medicine); FCPS (Internal Medicine), MRCP UK \\ (London), Consultant Internal Medicine, Assistant professor of medicine, Department of Internal Medicine, King \\ Faisal University, Hofuf 31982, Kingdom of Saudi Arabia. E-mail: drmmhashir@gmail.com
}

Received: September 19, 2016 Accepted: October 26, 2016 Online Published: November 30, 2016

doi:10.5539/gjhs.v9n6p145

URL: http://dx.doi.org/10.5539/gjhs.v9n6p145

\begin{abstract}
Introduction: Cancer is a major public health problem. Worldwide, colorectal cancer (CRC) is a leading cause of deaths due to cancer in both men and women. Among, Saudi men, CRC is the most common malignancy while it is the third most common among Saudi women. Over, two decades the incidence and deaths due to CRC have been steadily increasing in Saudi Arabia. Regular and timely screening has the potential in reducing the incidence and deaths due to colorectal cancer. The present study is conducted to evaluate the knowledge and awareness about colorectal cancer and its screening among the doctors.
\end{abstract}

Objectives: To measure the frequency of knowledge and awareness about colorectal cancer and its screening guidelines among doctors in Al-Ahssa.

Methods: A questionnaire based survey of the doctors (Specialists \& residents), working in different hospitals and primary health centers under the Ministry of Health in Al Ahssa region, Eastern province, KSA. Knowledge and awareness about colorectal cancer and its screening among the doctors is evaluated.

Results: Over $80 \%$ of the doctors knew, screening reduces deaths due to CRC. Only $60 \%$ were aware about the risk factors and less than $50 \%$ knew the clinical features of CRC. About $60 \%$ doctors agreed Colonoscopy is gold standard screening test. While, less than $60 \%$ knew the ideal age to initiate screening and the actual interval of screening tests in the standard risk and high-risk population. Fewer than $25 \%$ doctors were aware about the American cancer society recommended screening guidelines. Majority of the doctors expressed keen interest to know and receive information about $\mathrm{CRC}$ and its screening guidelines.

Conclusions: Regular and timely screening reduces deaths due to CRC. There is a need for improving knowledge and awareness of doctors about CRC and its screening. Awareness among the doctors improves uptake of screening by the general and high-risk population.

Keywords: colorectal cancer, screening, doctors, Kingdom of Saudi Arabia

\section{Introduction}

Cancer is a major public health problem. Worldwide Colorectal cancer CRC is one of the leading cancers in both men and women (Ferley, 2013; Bernard, 2014). In the United States, colorectal cancer is the third common cancer in both men and women (Seigel, 2014). As per the Saudi cancer registry 2010, CRC is the most common malignancy among Saudi men and third most common in women (Ministry, 2014; Eid, 2007). Over the past two decades, a steady increase in the incidence and deaths due to CRC has been reported from Saudi Arabia (Mosli, 2012; Ibrahim, 2008). Majority of the patients had an advanced stage disease and survival rates of $44.6 \%$, which is lower than the reported survival rates all over the world (Elsamany, 2014). Further, nearly half of the cases were diagnosed in individuals less than 50 years of age with mean age of 58 years, which is lower than reported from the developed countries (Aljebreen, 2007; Ibrahim, 2008). Colorectal cancer with its high incidence and a long interval between the appearance of the polyps and frank carcinoma is an ideal tumor for screening. Regular and timely screening helps in the detection and removal of both precancerous lesions and early stage cancer, there by 
reduces both the incidence and deaths due to CRC (Winawer, 1997; Burt, 2010). Several studies from Saudi Arabia and outside, stressed the need for preventive measures and early detection of the disease (Almurshed, 2009; Umer, 2009). Recently, a downward trend in both the incidence and mortality from CRC is reported from the United States. This positive outcome may be attributed to widespread implementation of screening programs along with better understanding of the pathogenesis and advances in the treatment (Edwards, 2006). The current ACS guidelines for CRC screening includes: Fecal occult blood testing (FOBT) - Annually, Sigmoidoscopy every 5 years and colonoscopy once every 10 years, all starting at age 50 years (Levin, 2008). Knowledge, awareness, and beliefs of the doctors about CRC and its screening is a major factor, motivating general population to undergo screening (Sheih, 2005; Gennarelli, 2005). Considering the important role of the doctors (Specialists and Residents) in the screening activities, the present study was conducted to prospectively evaluate the knowledge and awareness about CRC and its screening programs among the doctors, working in different hospitals and primary health care centers in $\mathrm{Al}$ Ahssa region, Eastern province of Kingdom of Saudi Arabia.

\section{Method}

Ours is a cross sectional study. Between, December 2014-September 2015, total 160 doctors employed in different hospitals and primary health centers, under Ministry of health, in Al Ahssa region, eastern province, KSA were evaluated. Questionnaire about the CRC and its screening guidelines was given to doctors by hand. The questionnaire was pilot tested on five internists for the content validity. The questionnaire was distributed to the doctors after seeking permission from the hospital authorities. A group of medical students involved in the research handed over questionnaire to the doctors during their free time in the hospital. The survey questionnaire took approximately 15 minutes to complete. Response to the questions were designed in the form of agree or disagree. Results of the survey are presented as percentages. Questionnaire has four sections- Section1: Demographic characteristics of the doctors, Section 2: Risk factors and the Symptoms of CRC, Section 3: CRC Screening guidelines recommended by the American cancer society and Section 4: Ideal screening test, timing and frequency of testing in standard and high risk individuals.

\subsection{Statistical Analysis}

Descriptive statistics is performed using the Statistical Package for the social sciences version 21.0 (SPSS). Variables are presented as frequencies and percentages.

\section{Results}

Total 160 doctors (Specialists 33\% and Residents 67\%) were evaluated using self-administered questionnaire. Internists were $59 \%$ and surgeons $41 \%$. Male doctors were $77 \%$ and Female $23 \%$. Nearly $85 \%$ doctors knew, screening reduces deaths due to CRC. While $73 \%$ knew the actual benefits of screening (detection and removal of polyps and precancerous lesions in asymptomatic individuals), only $50 \%$ doctors could define screening correctly (testing of asymptomatic individuals). About, $60 \%$ of the doctors knew the high risk factor for CRC such as diet rich in calories, fat and red meat. While less than $45 \%$ doctors knew about westernized life style and the risk of $\mathrm{CRC}-$ Physical inactivity, excess weight gain, excess alcohol consumption, and smoking. Less than $50 \%$ of the doctors knew the symptoms of CRC - Bleeding per rectum, constipation, altered bowel habits and pain abdomen. Over $95 \%$ of the doctors knew about the hereditary nature of CRC. Moreover, $60 \%$ knew colonoscopy is the gold standard screening test for CRC. Less than 25\% (21\%) doctors were aware about the American Cancer Society recommended screening guidelines and the actual interval of the screening-FOBT annually, Flexible Sigmoidoscopy every 5 years and colonoscopy once every 10 years. Ideal age to initiate screening in average risk individual (50 years) was known to $58 \%$ doctors while less than $50 \%$ knew the age to initiate screening in high-risk individuals (40 years). More than $85 \%$ agreed that, Knowledge and awareness about the CRC and its screening guidelines among the doctors would improve uptake of screening in the general population. In our survey more than $90 \%$ doctors expressed their interest to know and to receive information about CRC and its screening guidelines. 
Table 1. Demographics of the doctors

\begin{tabular}{lll}
\hline Total number of doctors, $\mathbf{N}=\mathbf{1 6 0}(\mathbf{1 0 0} \%)$ & Specialists $\mathbf{n}=\mathbf{5 2 ( 3 3 )}$ & Residents 108 (67) \\
\hline Male $=124(77 \%)$ & $44(28)$ & $80(50)$ \\
Female $=36(23 \%)$ & $08(05)$ & $28(17)$ \\
\hline
\end{tabular}

Table 2. About colorectal cancer \& screening

\begin{tabular}{ll}
\hline About colorectal cancer symptoms & Agreed (\%) \\
\hline Symptoms & $\mathbf{4 5}$ \\
Bleeding PR & $\mathbf{6 5}$ \\
Constipation & $\mathbf{2 5}$ \\
Altered bowel habits & $\mathbf{2 9}$ \\
Pain abdomen & $\mathbf{6 0}$ \\
Definition of screening: Screening done to detect & \\
Symptomatic Early stage cancer & $\mathbf{4 9}$ \\
Asymptomatic & $\mathbf{5 1}$ \\
Benefits of Screening & $\mathbf{7 3}$ \\
Detect early stage cancer & $\mathbf{8 3}$ \\
Reduces deaths due to cancer & $\mathbf{7 6}$ \\
Regular screening prevents cancer & $\mathbf{6 9}$ \\
Gold standard screening test & \\
Colonoscopy & $\mathbf{6 0}$ \\
Sigmoidoscopy & $\mathbf{2 7}$ \\
FOBT & $\mathbf{1 3}$ \\
Ideal timing to initiate screening & $\mathbf{5 3}$ \\
Average risk individuals -50 years & $\mathbf{5 8}$ \\
High risk individuals -40 years & $\mathbf{4 7}$ \\
Like to receive information about CRC and its screening & $\mathbf{8 7}$ \\
ACS recommended CRC screening guidelines & \\
FOBT - Annually; FS - 5 years; CS - 10 years & $\mathbf{2 1}$ \\
\hline
\end{tabular}




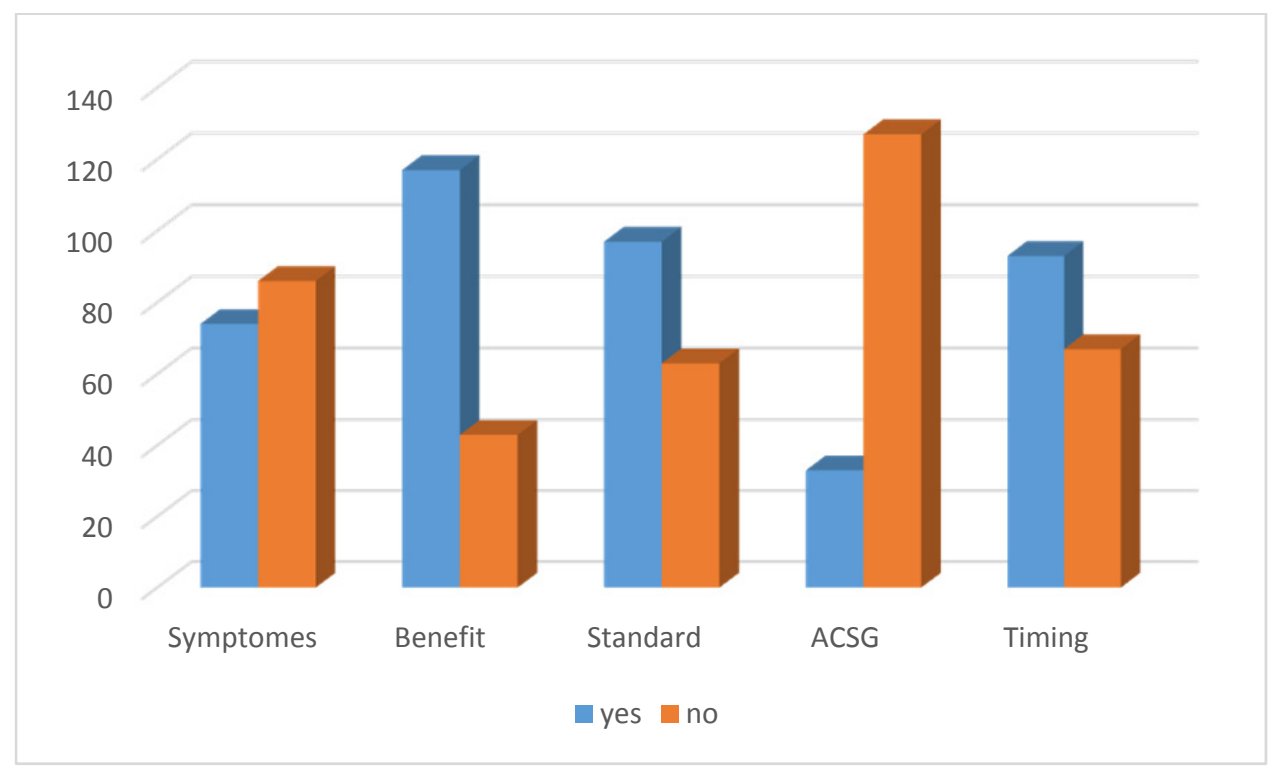

Graph 1.

\section{Discussion}

The primary objective of our study is to evaluate the awareness and understanding of the CRC and its screening modalities among the doctors working in different hospitals under ministry of health, in Al Ahssa region, eastern province, Kingdom of Saudi Arabia. Over $95 \%$ of the doctors considered CRC as a major public health problem and they admitted that screening would help in reducing the incidence and deaths due to CRC. Several studies from Saudi Arabia and outside have concluded and highlighted the need for screening to reduce deaths due to CRC (Mosli 2012, Elsamany 2014 and Aljebreen 2007). Over, 65\% of the doctors agreed Colonoscopy as gold standard test for screening. Several studies from Saudi Arabia strongly recommend population screening for CRC, as benefits outweigh the drawbacks (6). Physicians play a critical role in implementing guidelines and achieving public health targets for colorectal cancer screening (Brawarsky 2004). Saudi Arabia; patients attend the primary health centers for their first consult. Very little is known about the practice of CRC screening by primary care physicians, as there is no published data on the practice of colorectal cancer screening from this region. In the United States, practice of colorectal cancer screening is excellent, achieving $90-95 \%$ of health care providers recommending screening (Task Force 2002). Our study results showed that CRC screening is underutilized as more than half of the study subjects were not practicing CRC screening in spite of the documented survival benefit from CRC screening (Klabunde 2003, Mandel 2000 and Hardcastle 1996). This can be attributed to lack of information and knowledge among the doctors about the recommended screening guidelines and poor awareness about the timing of initiation of screening and its benefits. Seeff et al. concluded that lack of physician recommendation is one of the most common reasons for patients not undergoing screening (Seef 2004). Knowledge and awareness of doctor's about CRC and its screening modalities will have a great impact on the population screening, thereby reducing deaths due to CRC (Fedrici 2005). We are aware of the limitation of our study as it is a single time point. Secondly, it involves only those doctor's in the general hospitals and primary health centers under the ministry of health in the Al Ahssa region. Our results may not reflect the overall knowledge and awareness of all the doctors from the region as we have excluded doctors in the private setting, which is assumed to see almost an equal number of patients.

\section{Conclusions}

Regular and timely screening reduces deaths due to CRC. Awareness about CRC and its screening among the doctor's improves uptake of screening by the average and high-risk population. In our present survey, we found a sizeable percentage of doctor's have less clear information about the CRC screening guidelines. We therefore recommend and suggest that there is a need for large-scale educational programs, which keeps the doctor's updated with the latest screening guidelines.

\section{Competing Interests Statement}

The authors declare that there is no conflict of interests regarding the publication of this paper. 


\section{References}

Ferlay, J., Soerjomataram, I., Ervik, M., et al. GLOBOCAN 2012 v1.0, Cancer Incidence and Mortality Worldwide: IARC CancerBase No. 11 [Internet]. Lyon, France: International Agency for Research on Cancer; 2013. Retrieved from http://globocan.iarc.fr, accessed November 2016.

Siegel, R., Ma, J., Zou, Z., \& Jemal, A. (2015). Cancer statistics, 2014. CA Cancer J Clin, 65, 5-29. https://doi.org/10.3322/caac. 21254

Ministry of Health, cancer incidence and survival Report, Saudi Arabia, 2010, April 2014, Retrieved from http://www.scr.org.sa

Aleid, H. S., \& Al-Zahrani, A. (2007). Cancer Incidence and Survival Report Saudi Arabia. Retrieved from http://www.scr.org.sa

Mosli, M. H., \& Al-Ahwal, M. S. (2012) Colorectal cancer in the Kingdom of Saudi Arabia: need for screening. Asian PacificJournal of Cancer Prevention, 13(8), 6285-6288, 2012. https://doi.org/10.7314/APJCP.2012.13.12.6285

Ibrahim, E. M., Zeeneldin, A. A., El-Khodary, T. R., Al-Gahmi, A. M., \& Bin Sadiq, B. M. (2008). Past, present and future of colorectal cancer in the Kingdom of Saudi Arabia. Saudi J Gastroenterol, 14, 178-82. https://doi.org/10.4103/1319-3767.43275

Elsamany, S. A., Alzahrani, A. S., Mohamed, M. M., Elmorsy, S. A., Zekri, J. E., Al-Shehri, A. S., ... El-Taani, H. A. (2014). Clinico-pathological patterns and survival outcome of colorectal cancer in young patients: western Saudi Arabia experience. Asian Pac $J$ Cancer Prev, 15(13), 5239-5243. https://doi.org/10.7314/APJCP.2014.15.13.5239

Aljebreen, A. M. (2007). Clinico-pathological patterns of colorectal cancer in Saudi Arabia: Younger with an advanced stage presentation. Saudi Journal of Gastroenterology, 13(2), 84-87. https://doi.org/10.4103/1319-3767.32183

Ibrahim, E. M., Zeeneldin, A. A., El-Khodary, T. R., Al-Gahmi, A. M., \& Sadiq, B. M. B. (2008) "Past, present and future of colorectal cancer in the Kingdom of Saudi Arabia. Saudi Journal of Gastroenterology, 14(4), 178-182. https://doi.org/10.4103/1319-3767.43275

Winawer, S. J., Fletcher, R. H., Miller, L., Godlee, F., Stolar, M. H., Mulrow, C. D., et al. (1997). Colorectal-cancer screening: clinical guidelines and rationale. Gastroenterology, 112, 594-642. https://doi.org/10.1053/gast.1997.v112.agast970594

Burt, R. W., Barthel, J. S., Dunn, K. B., David, D. S., Drelichman, E., Ford, J. M., et al. (2010). NCCN clinical practice guidelines in oncology. Colorectal cancer screening. J Natl Compr Canc Net, 8, 8-61.

Almurshed, K. S. (2009). Colorectal cancer: case-control study of sociodemographic, lifestyle and anthropometric parameters in Riyadh. Eastern Mediterranean Health Journal, 15(4), 817-826.

Umar, A., \& Greenwald, P. (2009). Alarming colorectal cancer incidence trends: a case for early detection and prevention. Cancer epidemiol Biomarkers Prev. Jun, 18(6), 1672-1683. https://doi.org/10.1158/1055-9965.EPI-09-0320

Edwards, B. K., Ward, E., Kohler, B. A., Eheman, C., Zauber, A. G., Anderson, R. N., et al. (2010). Annual Report to the Nation on the Status of Cancer, 1975-2006, Featuring Colorectal Trends and Impact of Interventions (Risk Factors, Screening, and Treatment) to Reduce Future Rates. Cancer, 116(3), 544-73. https://doi.org/10.1002/cncr.24760

Levin, B., Liberman, D. A., McFarland, B., et al. (2008). Screening and surveillance for the early detection of colorectal cancer and adenomatous polyps, 2008: a joint guideline from American cancer Society, the US military Task Force on colorectal cancer and the American College of Radiology. Gastroenterology. 134(5), 1570-1595. https://doi.org/10.3322/ca.2007.0018

Shieh, K., Gao, F., Ristvedt, S., Schootman, M., \& Early, D. (2005) The impact of physicians' health beliefs on colorectal cancer screening practices. Dig Dis Sci, 50, 809-814. https://doi.org/10.1007/s10620-005-2644-3

Gennarelli, M., Jandorf, L., Cromwell, C., Valdimarsdottir, H., Redd, W., \& Itzkowitz, S. (2005). Barriers to colorectal cancer screening:inadequate knowledge by physicians. Mt Sinai J Med, 72, 36-44.

Brawarsky, P., Brooks, D. R., Mucci, L. A., \& Wood, P. A. (2004). Effect of physician recommendation and patient adherence on rates of colorectal cancer testing. Cancer detect Prev, 28, 260-8. 
https://doi.org/10.1016/j.cdp.2004.04.006

U.S. Preventive services Task force: Screening for colorectal cancer; recommendation and rationale. Ann Intern Med 2002, 137, 129-131. https://doi.org/10.7326/0003-4819-137-2-200207160-00014

Klabunde, C. N., Frame, P. S., Meadow, A., Jones, E., Nadel, M., \& Vernon, S. W. (2003). A national survey of primary care physicians' colorectal cancer screening recommendations and practices, Preventive Medicine, 36(3), 352-362. https://doi.org/10.1016/S0091-7435(02)00066-X

Mandel, J. S., church, T. R., Bond, J.H,, Ederer, F., Geisser, M. S., Mongin, S. J., Snover, D. C., \& Schuman, L. M. (2000). The effect of fecal occult-blood screening on the incidence of colorectal cancer. N Engl J Med, 343, 1603-1607. https://doi.org/10.1056/NEJM200011303432203

Hardcastle, J. D., Chamberlain, J. O., Robinson, M. H., Moss, S. M., Amar, S. S., Balfour, T. W., ... Mangham C. M. (1996) Randomized controlled trial of Faecal-occult-blood screening for colorectal cancer. Lancet, 348, 1472-1477. https://doi.org/10.1016/S0140-6736(96)03386-7

Seeff, L. C., Nadel, M. R., Klabunde, C. N., et al. (2004). Patterns and predictors of colorectal cancer test use in the adultsU.S. Population. Cancer, 100, 2093-103. https://doi.org/10.1002/cncr.20276

Federici, A., Giorgi Rossi, P., Bartolozzi, F., Farchi, S., Borgia, P., \& Guasticchi, G. (2005). Survey on colorectal cancer screening knowledge, attitudes and practices of general practice Physicians in Lazio, Italy. Prev Med, 41, 30-35. https://doi.org/10.1016/j.ypmed.2004.11.010

\section{Copyrights}

Copyright for this article is retained by the author(s), with first publication rights granted to the journal.

This is an open-access article distributed under the terms and conditions of the Creative Commons Attribution license (http://creativecommons.org/licenses/by/4.0/). 